Article

\title{
Depigmenting Effect of Resveratrol Is Dependent on FOXO3a Activation without SIRT1 Activation
}

\author{
Soon-Hyo Kwon, Hye-Ryung Choi, Youn-A Kang and Kyoung-Chan Park* \\ College of Medicine, Seoul National University, Seoul National University Bundang Hospital, Gyeonggi 13620, \\ Korea; soonhyo17@hanmail.net (S.-H.K.); hrchoi73@snu.ac.kr (H.-R.C.); k-youn-a@snu.ac.kr (Y.-A.K.) \\ * Correspondence: gcpark@snu.ac.kr; Tel.: +82-31-787-7311
}

Academic Editor: Terrence Piva

Received: 29 March 2017; Accepted: 30 May 2017; Published: 7 June 2017

\begin{abstract}
Resveratrol exhibits not only anti-melanogenic property by inhibiting microphthalmia-associated transcription factor (MITF), but also anti-aging property by activating sirtuin-1 (SIRT1). In this study, the relationship between depigmenting effect of resveratrol and SIRT1/forkhead box O (FOXO) 3a activation and was investigated. Resveratrol suppressed melanogenesis by the downregulation of MITF and tyrosinase via ERK pathway. Results showed that the expression of both SIRT1 and FOXO3a were increased. It is reported that SIRT1 is critical regulator of FOXO-mediated transcription in response to oxidative stress. However in our study, FOXO3a activation appeared earlier than that of SIRT1. Furthermore, the effect of resveratrol on the levels of MITF and tyrosinase was suppressed when melanocytes were pre-treated with SP600125 (JNK inhibitor). However, pre-treatment with SIRT1 inhibitor (EX527, or sirtinol) did not affect the levels of MITF and tyrosinase. Therefore, resveratrol inhibits melanogenesis through the activation of FOXO3a but not by the activation of SIRT1. Although SIRT1 activation by resveratrol is a well-known mechanism of resveratrol-induced antiaging effects, our study showed that not SIRT1 but FOXO3a activation is involved in depigmenting effects of resveratrol.
\end{abstract}

Keywords: extracellular signal-regulate kinase; forkhead box O; melanogenesis; resveratrol; sirtuin-1

\section{Introduction}

The aging process of skin includes pigmentary changes, such as melasma or senile lentigo. Though the mechanism of these phenomena is not clearly understood, much evidence has revealed the association of skin aging and pigmentary changes. Increased levels of melanogenic cytokine or factors were demonstrated in aged skin and chronic ultraviolet (UV)-exposed skin. A significant positive correlation was found between age and interleukin (IL)- $1 \alpha$ secretion, which stimulate melanocyte proliferation and tyrosinase activity via hepatocyte growth factor (HGF) and endothelin (ET)-1 secretion [1]. Elevated levels of HGF, keratinocyte growth factor (KGF) and stem cell factor (SCF) were demonstrated in the dermis of senile lentigo [2]. UVB irradiation promotes keratinocytes to secret SCF, basic fibroblast growth factor (bFGF), IL-1, ET-1, inducible nitric oxide synthase, $\alpha$-melanocyte-stimulating hormone $(\alpha-\mathrm{MSH})$, adrenocorticotropic hormone, and prostaglandin E2 [3-8]. Furthermore, basement membrane disruption, a characteristic senile change of skin, was observed in 83 to $95 \%$ of the lesional skin in patients with melasma [9].

These findings suggest that depigmenting treatment needs to be accompanied by antiaging treatment. Resveratrol is a hydroxystilbene compound found in grapes, red wine, berries, and other plants and possesses anti-cancer, anti-hyperlipidemia, and anti-aging properties [10]. It has been also reported that resveratrol inhibits the activity of microphthalmia-associated transcription factor (MITF) [11]. Because MITF is a major regulator of melanogenesis [12,13], resveratrol reduced UVB-induced pigment deposition in Yucatan swine [11]. On the other hand, it was reported 
that tyrosinase inhibition by resveratrol results from a post-transcriptional change of tyrosinase, a rate-limiting step for melnogenesis, but not from MITF alterations [14,15]. One study demonstrated the antioxidant property of resveratrol, which could inhibit tyrosinase [16]. However, we observed that resveratrol at concentrations of $0.1-10 \mu \mathrm{M}$ did not inhibit tyrosinase directly nor regulate tyrosinase post-transcriptionally [17]. All these findings suggest that depigmenting mechanism of resveratrol still needs further investigation.

Sirtuin-1 (SIRT1) is an NAD+-dependent protein deacetylase, which decreases reactive oxygen species (ROS) levels. It is also involved in variety of cellular processes, such as apoptosis, cell cycle, DNA repair, energy metabolism, and development [18-21]. SIRT1 modulates two important transcription factors which influence cell survival and death-p53 and forkhead box O (FOXO) [22-24]. While there exist p53-independent cell protective pathway, FOXOs were found to be indispensable for SIRT1-dependent cell survival against oxidative stress [25]. Resveratrol activates SIRT1, and thus protects various organs against aging [26,27]. Administration of resveratrol showed beneficial effects against cardiovascular and neurodegenerative diseases [28]. In cultured primary human keratinocytes, resveratrol prevents oxidative stress-induced senescence and proliferative dysfunction by activating the AMP-activated protein kinease (AMPK)-FOXO3a cascade [29]. Involvement of SIRT1 and FOXO in resistance against ROS, insulin signaling, and cellular longevity proposes that modulation of these targets could protect or reverse aged skin or skin pigmentation [30]. However, the relationship between resveratrol-induced depigmenting effects and SIRT1/FOXO3a activation are not clearly demonstrated yet. In this study, we investigated the role of SIRT1 and FOXO3a activation in melanogenesis.

\section{Results}

Scavenging activity of resveratrol was tested by DPPH assay. At $0.1 \mu \mathrm{M}$, resveratrol exhibited less than $20 \%$ of scavenging activity. The antioxidant activity rose dramatically with increasing concentrations of resveratrol (Figure S1). Resveratrol was found to be non-cytotoxic to normal human melanocytes up to $50 \mu \mathrm{M}$ of concentration (Figure S2). To study the ROS scavenging effects, normal human melanocytes were pretreated with $50 \mu \mathrm{M}$ of resveratrol for $24 \mathrm{~h}$. Then, $\mathrm{H}_{2} \mathrm{O}_{2}(50 \mu \mathrm{M})$ was added and examined $24 \mathrm{~h}$ later. Results showed that hydrogen peroxide-induced oxidative stress can be ameliorated by $50 \mu \mathrm{M}$ of resveratrol pre-treatment (Figure 1).

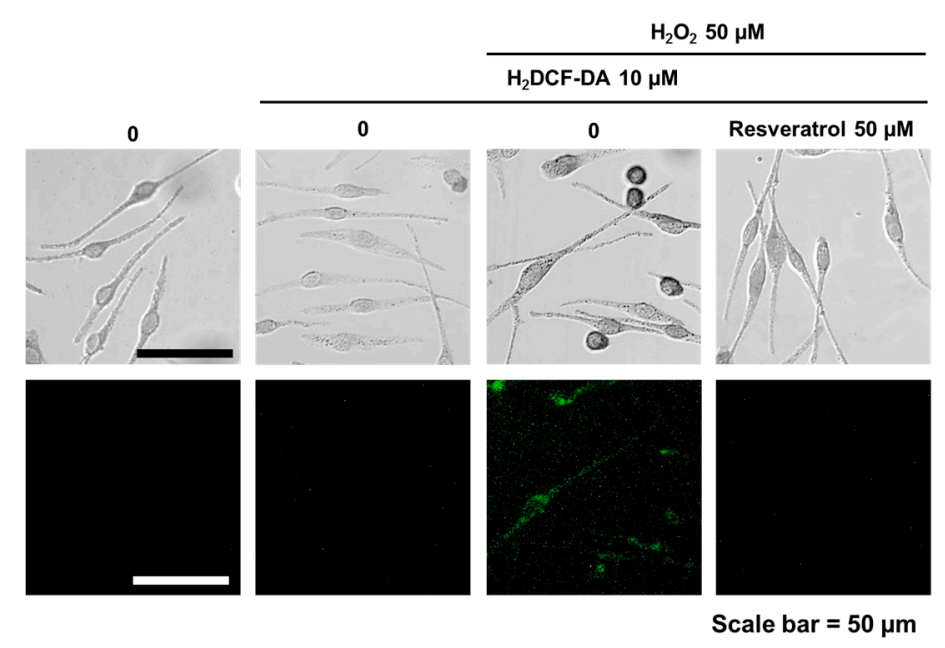

Figure 1. Fluorescent microscopic observation. After resveratrol (50 $\mu \mathrm{M}$, overnight) treatment, cells then treated by hydrogen peroxide $(50 \mu \mathrm{M}$, overnight). Fluorescent microscopic examination was done after $\mathrm{H}_{2}$ DCF-DA $(10 \mu \mathrm{M})$ staining.

Based on cytotoxicity data and ROS scavenging study, $50 \mu \mathrm{M}$ was selected for further study. After resveratrol treatment, tyrosinase activity was measured. Cultured normal human melanocytes were 
incubated with resveratrol for three days. After washing, the cells were lysed. Each well of 96-well plate was filled with $90 \mu \mathrm{L}$ of lysate and $10 \mu \mathrm{L}$ L-DOPA, then incubated at $37^{\circ} \mathrm{C}$. ELISA was used to measure the absorbance at $475 \mathrm{~nm}$. The activity of tyrosinase was decreased in a dose-dependent manner (Figure 2a). Melanin assay also showed similar results after three days (Figure 2b). However, no direct inhibition of tyrosinase activity was observed at the concentration of up to $500 \mu \mathrm{M}$ (Figure 2c).
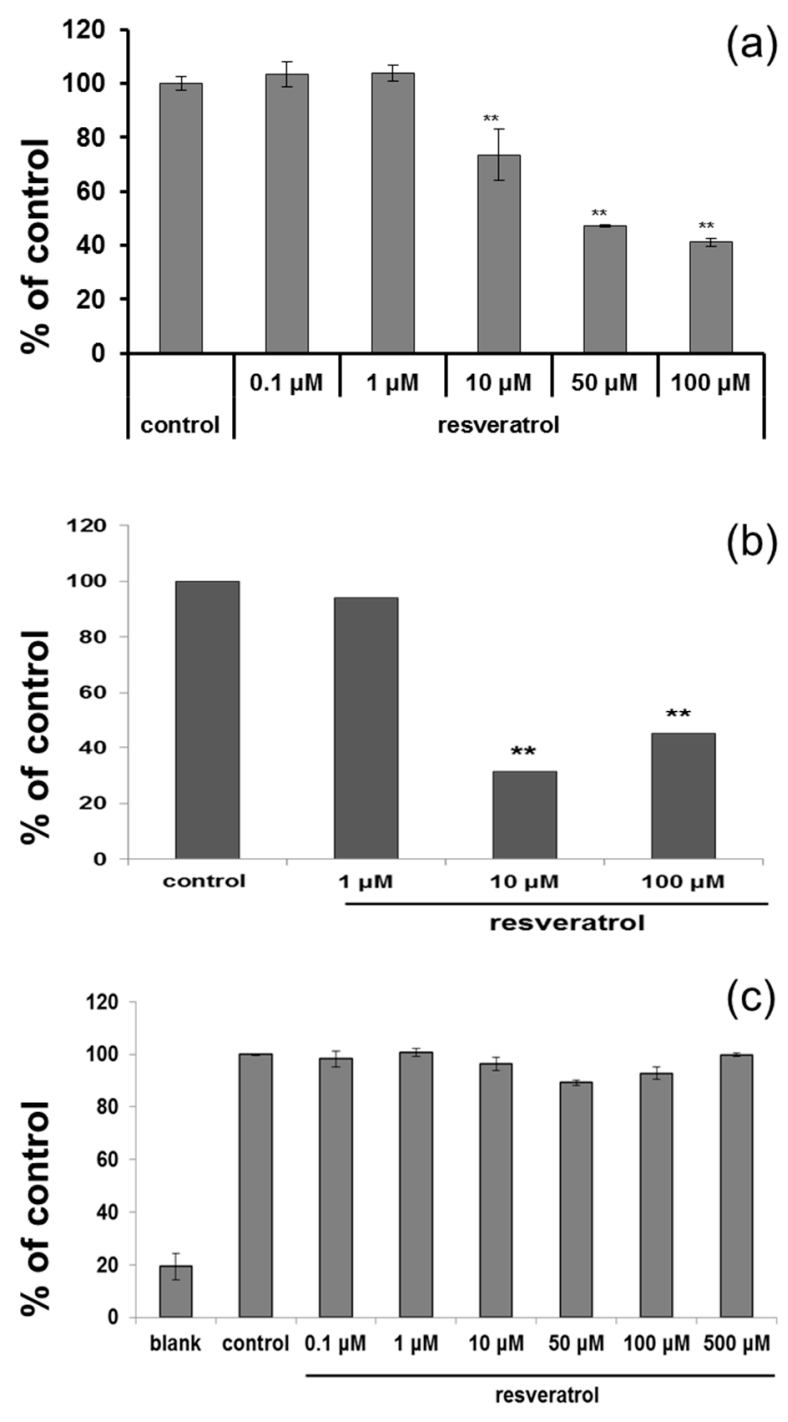

Figure 2. (a) ELISA was carried after adding L-DOPA to normal human melanocytes which were treated with resveratrol for three days to measure tyrosinase activity; (b) Cells were treated with resveratrol for $72 \mathrm{~h}$ and amount of melanin was measured; (c) Direct inhibition of tyrosinase by resveratrol was studied using a cell-free system.

After normal human melanocytes were treated with resveratrol at the concentrations of 10 to $100 \mu \mathrm{M}$ for $24 \mathrm{~h}$, the levels of extracellular signal-regulate kinase (ERK), MITF, and tyrosinase were investigated via western blot analysis. Resveratrol decreased the levels of tyrosinase and MITF in a dose-dependent manner (Figure 3). Activation of ERK was observed and results verified that the activation of ERK pathway is involved in the inhibition of MITF (Figure S3). Then, the activation of SIRT1 and FOXO3a were investigated. Results revealed that levels of SIRT1 and FOXO3a were also increased in normal human melanocytes after treatment with resveratrol for $24 \mathrm{~h}$ (Figure 3). It was reported that FOXO3a is a downstream pathway of SIRT1. Thus, we investigated the time-dependent 
changes of SIRT1 and FOXO3a after treating cell with $50 \mu \mathrm{M}$ of resveratrol. Interestingly, our results showed that elevation of FOXO3 appeared earlier than that of SIRT1 (Figure 4).

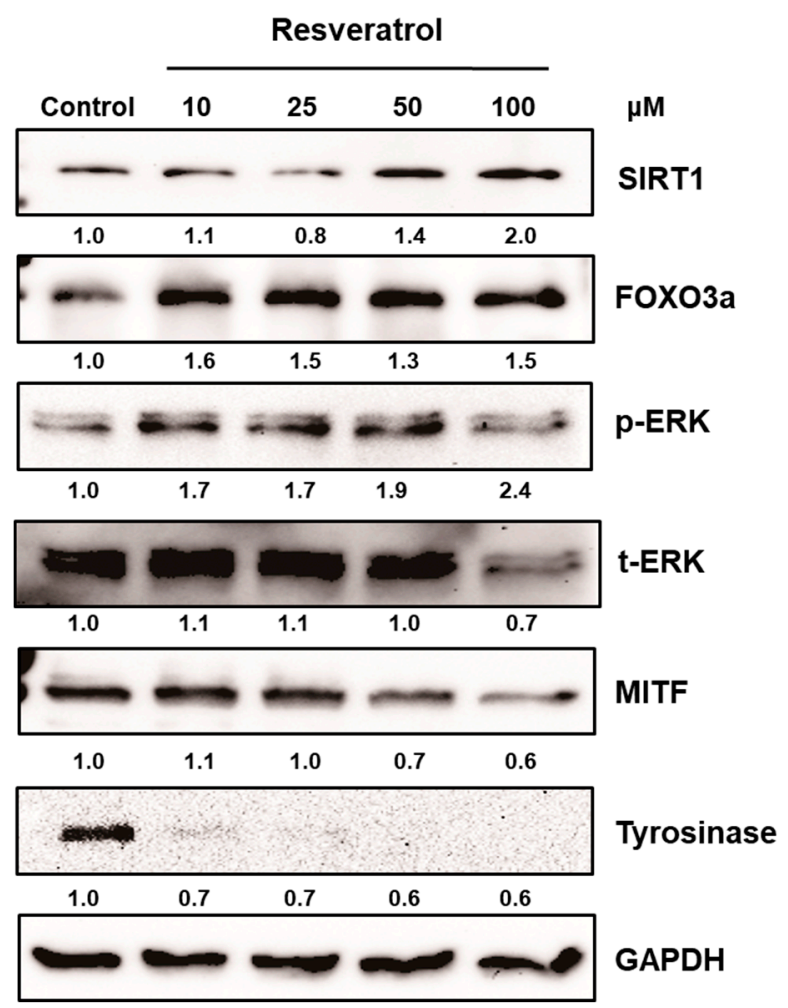

Figure 3. Normal human melanocytes were treated with 10 to $100 \mu \mathrm{M}$ of resveratrol for $24 \mathrm{~h}$. Then, the levels of ERK, MITF, tyrosinase, SIRT1, and FOXO3a were investigated.

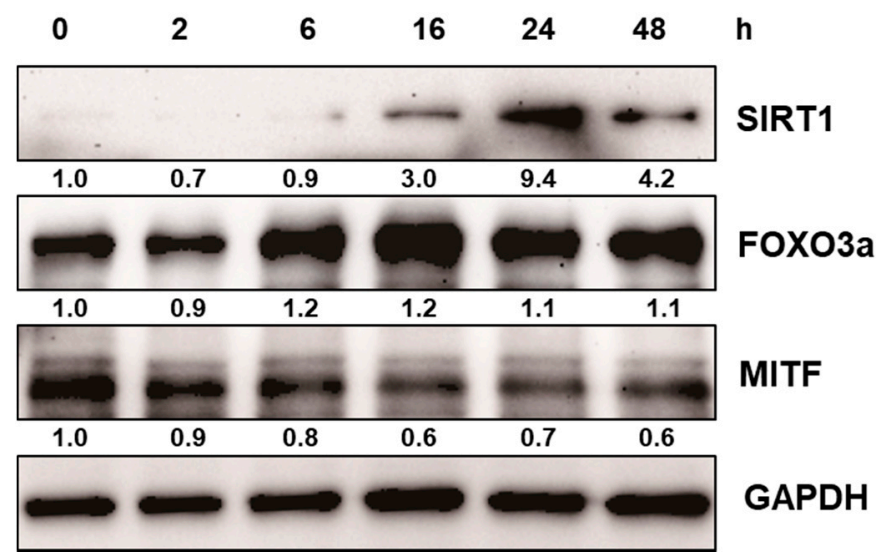

Figure 4. Time-dependent changes of SIRT1 and FOXO3a were investigated after treating normal human melanocytes with $50 \mu \mathrm{M}$ of resveratrol.

In order to analyze the role of SIRT1 or FOXO3a in depigmenting effect of resveratrol, normal human melanocytes were treated with resveratrol after pre-treatment with EX527 (SIRT1 inhibitor) and SP600125 (JNK inhibitor). Resveratrol treatment for $24 \mathrm{~h}$ effectively lowered the levels of MITF and tyrosinase (Figure 5). However, pretreatment of EX527 did not change the expressions of MITF and tyrosinase. In contrast, pre-treatment with SP600125 abolished the effect of resveratrol and consequently increased the level of MITF and tyrosinase. These findings suggested that SIRT1 activation is not related with resveratrol induced depigmentation. To confirm the role of SIRT1 
on the depigmenting property of resveratrol, cells were pre-treated with sirtinol (SIRT1 inhibitor) to confirm the effect of SIRT1 on MITF and tyrosinase. Results showed that pre-treatment with sirtinol did not affect the effects of resveratrol on MITF and tyrosinase as with EX527 (Figure 6).

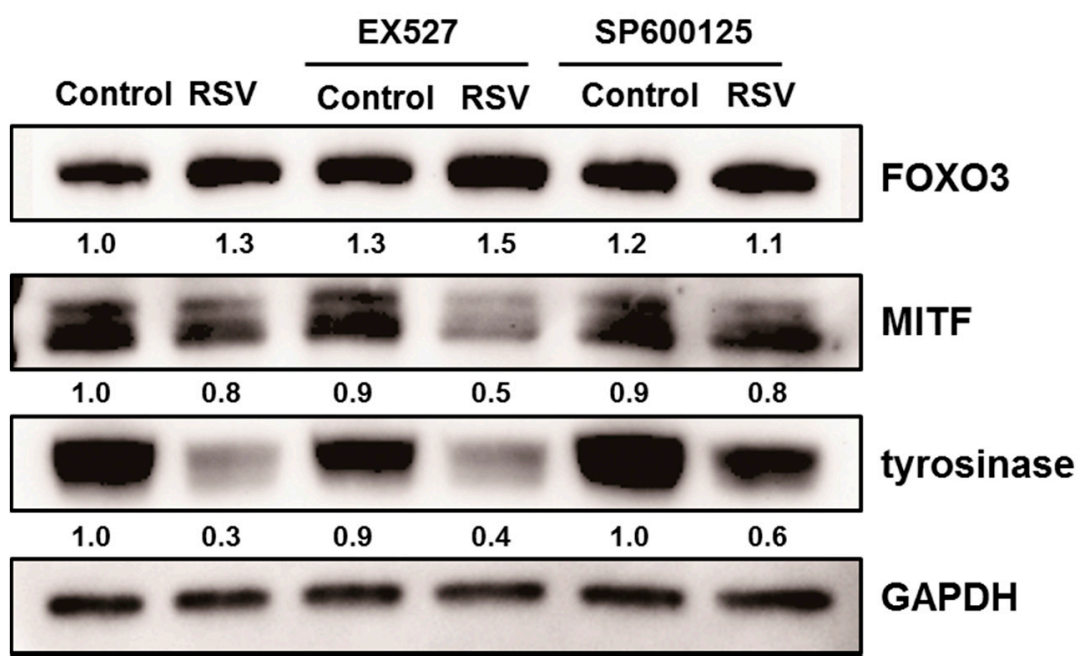

Figure 5. Normal human melanocytes were treated with resveratrol $(50 \mu \mathrm{M})$ after pre-treated with EX527 (SIRT1 inhibitor) and SP600125 (JNK inhibitor).

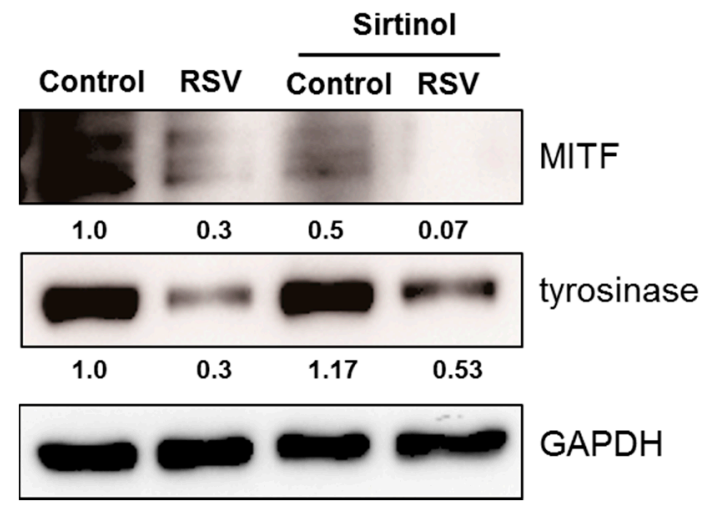

Figure 6. Normal human melanocytes were treated with resveratrol $(50 \mu \mathrm{M})$ with or without pre-treatment with sirtinol (SIRT1 inhibitor).

Fluorescent microscopic examination also showed similar results. The staining intensity of SIRT1 and FOXO3a was observed at a time-dependent manner after treating normal human melanocytes with resveratrol (Figure 7). At $6 \mathrm{~h}$ after resveratrol treatment, SIRT1 and FOXO3a appeared simultaneously. 
(a)

Resveratrol $50 \mu \mathrm{M}$
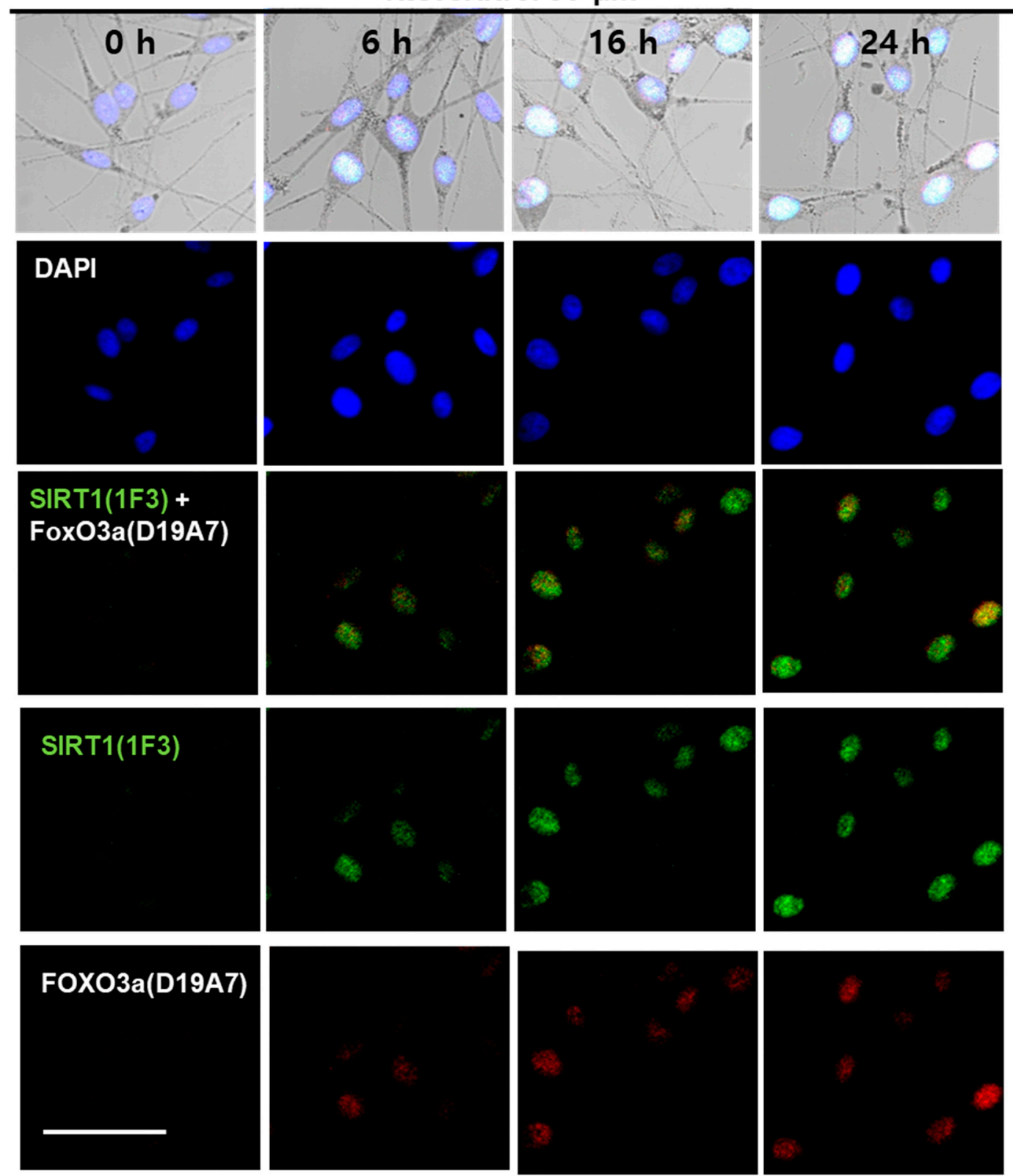

(b)

SIRT1(1F3)
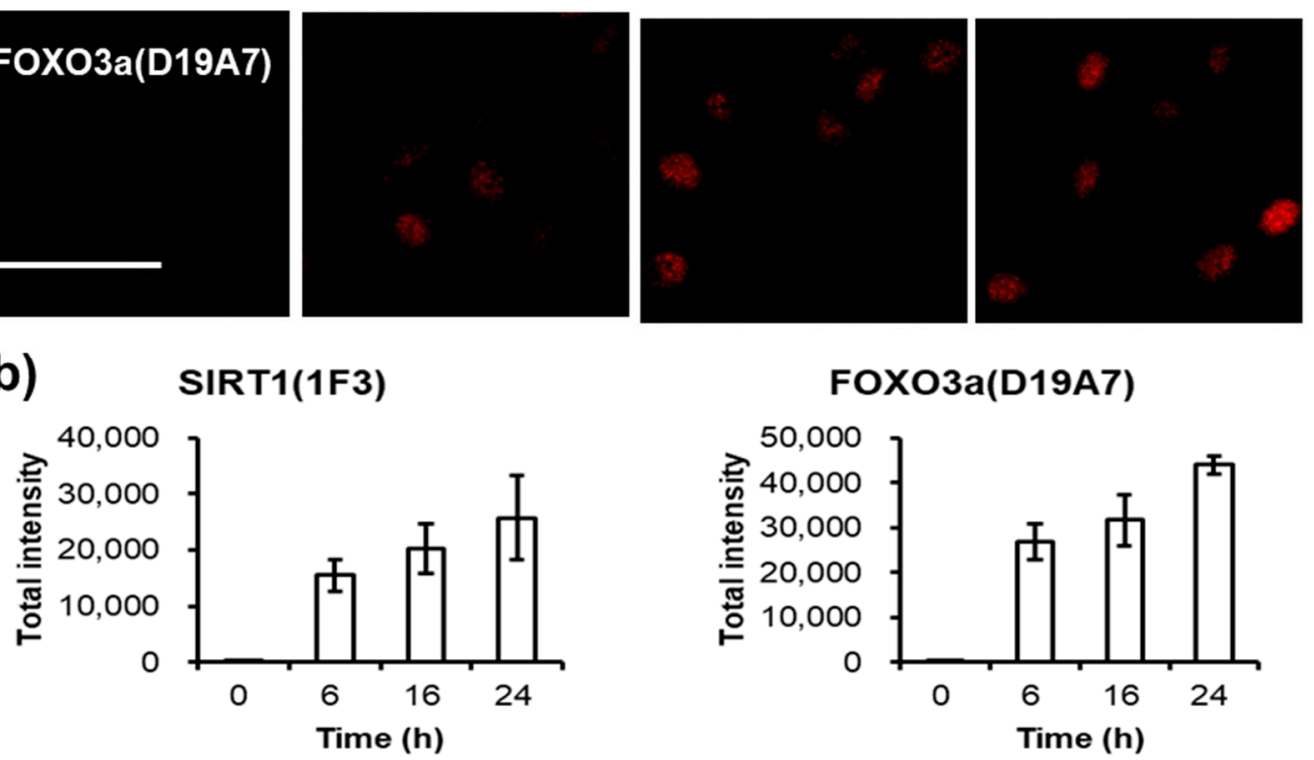

FOXO3a(D19A7)

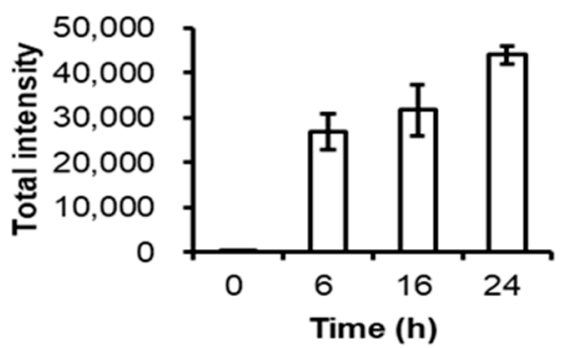

Figure 7. Fluorescent microscopic observation of SIRT1, FOXO3a in resveratrol-treated normal human melanocytes. (a) After resveratrol treatment, cells were stained at different time points $(0,6,16$, and $24 \mathrm{~h})$; (b) Staining intensity of SIRT1 and FOXO3a after resveratrol treatment at different time points $(0$, 6,16 , and $24 \mathrm{~h}$ ). Scale bar $=50 \mu \mathrm{m}$. 


\section{Discussion}

In this study, we found that resveratrol may inhibit tyrosinase through ERK and MITF pathway (Figure S2). In addition, direct inhibitory effect on tyrosinase was not observed [17]. Although there can be some variations, our study show that resveratrol suppressed tyrosinase levels very effectively by $24 \mathrm{~h}$ treatment (Figure 3). Though a few studies have suggested that resveratrol might inhibit tyrosinase activity via post-transcriptional regulation of tyrosinase [14], our results showed that resveratrol works through signaling pathways rather than direct inhibition of tyrosinase. Thus, the signaling mechanism of resveratrol in normal human melanocytes was analyzed. Our result also demonstrated that resveratrol could increase SIRT1 (known as longevity protein) and FOXO3a in normal human melanocytes. FOXO3a is a member of FOXO transcription factors which are involved in cellular signaling critical to anti-aging in response to a various stimuli, including insulin, insulin growth factor (IGF), ROS, and cytokines [31]. Recently, FOXO3a was found to be an anti-melanogenic factor that mediates antioxidant-induced depigmentation [31]. In addition, a significant relationship between rs4946936 polymorphism of FOXO3a gene and the occurrence of vitiligo has been demonstrated [32]. Because FOXO3a is modulated by SIRT1, it was hypothesized that resveratrol may increase SIRT1 and the following activation of FOXO3a may be a mechanism of depigmenting effects of resveratrol. In order to study the chronological sequence, we checked the time-dependent changes of SIRT1 and FOXO3a after resveratrol treatment. Unexpectedly, FOXO3a activation appeared earlier than that of SIRT1. Thus, FOXO3a may not be a downstream pathway in resveratrol-induced depigmenting effects.

To investigate the role of SIRT1 and FOXO3a in resveratrol-induced depigmentation, EX527 (SIRT1 inhibitor), and SP600125 (JNK inhibitor) were pre-treated before resveratrol treatment. As expected, the levels of MITF and tyrosinase were decreased after resveratrol treatment. However, the decreased levels of MITF and tyrosinase were restored by the pre-treatment of SP600125. In contrast, pre-treatment with EX527 did not affect the levels of MITF and tyrosinase. It means that FOXO3 has an important role in resveratrol-induced depigmentation process compared to SIRT1 activation. Because there is no specific FOXO3a inhibitor, SP600125 (JNK inhibitor) was used to study the role of FOXO3a in this study (Figure 5). Furthermore, the effects of LY294002 (PI3K inhibitor) were investigated and similar results were obtained (data not shown). Thus, these results suggest that FOXO3a is important mediator in resveratrol mediated depigmentation.

As described, EX527 did not show any effects on resveratrol induced depigmentation. It means that SIRT1 is not involved in resveratrol mediated depigmentation. To confirm the role of SIRT1, sirtinol (another kind of SIRT1 inhibitor) was pre-treated before resveratrol treatment. Results showed that sirtinol also did not reverse the effects of resveratrol on the levels of MITF and tyrosinase either. Therefore, these findings confirm that SIRT1 activation is not involved in resveratrol-induced depigmentation.

Finally, we checked the activation of SIRT1 and FOXO3a by confocal microscopic examination. Results showed that both SIRT1 and FOXO3a began to increase at $6 \mathrm{~h}$ after resveratrol treatment. These results are consistent with those by western blotting although the SIRT1 levels were weak by western blotting. Thus, confocal microscopic examination did show again that FOXO3a is not downstream pathway of SIRT1 when melanocytes were treated with resveratrol.

\section{Materials and Methods}

\subsection{Reagents}

SP600125 was obtained from Calbiochem (420119, Darmstadt, Germany). EX527 (203044) and sirtnol (s7942) was purchased from Sigma-Aldrich Co. (St. Louis, MO, USA).

Antibodies that recognize tyrosinase (sc7833) and GAPDH (sc-25778) were purchased from Santa Cruz Biotechnology (Santa Cruz, CA, USA). Antibodies recognize total (phosphorylated and non-phosphorylated) ERK1/2 (9102), phospho-specific ERK1/2 (Thr202/Tyr204, 9101S), FoxO3a (12829S), and SirT1 (8469s) were purchased from Cell Signaling Technology (Danvers, MA, USA). 
Antibody to MITF (MS-771-PI) was purchased from ThermoScientific Nunc (Rochester, NY, USA). For confocal staining, Alexa Fluo488 chicken anti-rabbit IgG (H + L) (A21441, Molecular Probes, Eugene, OR, USA), and Alexa Fluo555 donkey anti-goat IgG (H + L) (A21432, Molecular Probes, Eugene, OR, USA) were obtained from Invitrogen (Carlsbad, CA, USA).

\subsection{DPPH Assay of Resveratrol}

To measure the antioxidant property of resveratrol, DPPH assay was used. Five concentrations of resveratrol were tested and each sample of stock solution $(2 \mu \mathrm{L}$ of $100 \times)$ was added to $80 \mu \mathrm{L}$ of $0.25 \mathrm{mM}$ DPPH and $118 \mu \mathrm{L}$ of $70 \%$ ethanol, to produce a final DPPH concentration of $0.1 \mathrm{mM}$. The mixture was vigorously shaken and left to stand for $30 \mathrm{~min}$ in the dark, and its absorbance was measured at $517 \mathrm{~nm}$ using an ELISA reader (TECAN, Salzburg, Austria).

\subsection{ROS Scavenging Effects}

Normal human melanocytes (NHMs) from teenager foreskin were cultured in modified MCDB 153 and incubated in a humidified incubator with $5 \% \mathrm{CO}_{2}$ at $37^{\circ} \mathrm{C}[33,34]$. The cells were incubated after adding $50 \mu \mathrm{M}$ of resveratrol. After $24 \mathrm{~h}$, hydrogen peroxide $(50 \mu \mathrm{M})$ was added and incubated for another $24 \mathrm{~h}$. Then, cells were stained with $\mathrm{H}_{2}$ DCF-DA (10 $\mu \mathrm{M}$ in PBS) for $30 \mathrm{~min}$ for fluorescent microscope examination.

\subsection{Cell Culture and Viability}

Normal human melanocytes were also cultured in modified MCDB $153[33,34]$. The cells were incubated another $2 \mathrm{~h}$ after adding CCK-8 solution (CK04, Dojindo, Rockville, MD, USA) to the cells. SpectraMax Plus Microplate Reader (Molecular Devices, Sunnyvale, CA, USA) was used to determine the quantity of water-soluble formazan produced by dehydrogenase activity of the cells [35].

\subsection{Tyrosinase Activity and Melanin Amount}

Cultured normal human melanocytes were incubated with resveratrol for three days. After washed with cold PBS, the cells were lysed with phosphate buffer ( $\mathrm{pH}$ 6.8). Freezing-and-thawing broke down the cells, and the lysates were centrifuged at $10,000 \times g$ for $5 \mathrm{~min}$. Each well of 96-well plate was filled with $90 \mu \mathrm{L}$ of lysate and $10 \mu \mathrm{L}$ L-DOPA, then incubated at $37^{\circ} \mathrm{C}$. ELISA was used to measure the absorbance at $475 \mathrm{~nm}$ every $10 \mathrm{~min}[35,36]$.

Melanin contents were measured. Briefly, cells were treated with resveratrol for $72 \mathrm{~h}$. Cell pellets were then dissolved in $1 \mathrm{~mL}$ of $1 \mathrm{~N} \mathrm{NaOH}$ at $100{ }^{\circ} \mathrm{C}$ for $30 \mathrm{~min}$ and centrifuged for $20 \mathrm{~min}$ at $16,000 \times \mathrm{g}$. Optical densities (OD) of the supernatants were measured at $400 \mathrm{~nm}$ using an ELISA reader. A standard synthetic melanin curve (0 to $300 \mathrm{mg} / \mathrm{mL}$ ) was prepared in triplicate for each experiment.

Direct inhibition of tyrosinase induced by resveratrol was verified through a cell-free system. $20 \mu \mathrm{L}$ of mushroom tyrosinase was added to $70 \mu \mathrm{L}$ of phosphate buffer which contained resveratrol, followed by $10 \mu \mathrm{L}$ of $10 \mathrm{mM}$ L-DOPA. The absorbance at $475 \mathrm{~nm}$ was determined after incubating the mixture at $37^{\circ} \mathrm{C}$ for $20 \mathrm{~min}$ [35].

\subsection{Western Blot Analysis}

The cells were placed in a cell lysis buffer $(62.5 \mathrm{mM}$ Tris- $\mathrm{HCl}(\mathrm{pH} 6.8), 2 \%$ SDS, 5\% $\beta$-mercaptoethanol, $2 \mathrm{mM}$ phenylmethylsulfonyl fluoride, protease inhibitors (CompleteTM, Roche, Mannheim, Germany), $1 \mathrm{mM} \mathrm{Na} \mathrm{VO}_{4}, 50 \mathrm{mM} \mathrm{NaF}$, and $10 \mathrm{mM}$ EDTA) [37]. SDS-PAGE separated $10 \mu \mathrm{g}$ of protein per lane. The protein were blotted on the membranes and saturated with $5 \%$ dried milk. The blots were incubated with the primary antibodies at 1:1000 dilution, and then with horseradish peroxidase-conjugated secondary antibody. The enhanced chemiluminescence plus kit (Amersham International, Little Chalfont, UK) was used to detect the antibodies [35]. 


\subsection{Fluorescence Microscopic Examination}

80,000 normal human melanocytes were placed into 2-well chamber slides (Thermo Scientific Nunc, Rochester, NY, USA) and were treated with $20 \mu \mathrm{M}$ of resveratrol. Culture of the cells was ceased at various time points during $24 \mathrm{~h}$, followed by the fixation of the cells in $4 \%$ paraformaldehyde for $10 \mathrm{~min}$. The cells were processed with $0.2 \%$ Triton X-100, 5\% normal goat serum, and then incubated with the primary antibody. Alexa Fluo $488^{\circledR}$ goat anti-rabbit IgG (A11008, Molecular Probes ${ }^{\circledR}$, Invitrogen, Carlsbad, CA, USA) at 1:1000 dilution was used to detect fluorescence [35].

\subsection{Statistics}

Statistical analyses were conducted using Microsoft Excel (Microsoft Corporation, Redmond, WA, USA) and IBM SPSS Statistics 22 (IBM Corporation, Armonk, NY, USA). Student's t-test was used to measure differences among groups. $p>0.05$ was considered to indicate statistical significance.

\section{Conclusions}

Our study verified that resveratrol could inhibit melanogenesis through the downregulation of MITF and tyrosinase through ERK pathway. In addition, we also confirmed that resveratrol was not a good direct inhibitor of tyrosinase in normal human melanocytes. Signaling pathway was analyzed and our findings clearly demonstrated that resveratrol may inhibit melanogenesis through the activation of FOXO3a but not by the activation of SIRT1. Although SIRT1 activation by resveratrol is a well-known mechanism of antiaging effects, our results suggested that SIRT1 is not involved in depigmenting effects of resveratrol.

Supplementary Materials: Supplementary materials can be found at www.mdpi.com/1422-0067/18/6/1213/s1.

Acknowledgments: This study was supported by a grant from the Korean Health Technology R\&D Project, Ministry of Health \& Welfare, Korea (Grant number: HN14C0094).

Author Contributions: Hye-Ryung Choi and Kyoung-Chan Park conceived and designed the experiments; Hye-Ryung Choi, Hyun-Sun Lee and Youn-A Kang performed the experiments; Kyoung-Chan Park and Soon-Hyo Kwon analyzed the data; Soon-Hyo Kwon contributed reagents, materials, and analysis tools; Soon-Hyo Kwon wrote the paper.

Conflicts of Interest: The authors declare no conflict of interest.

$\begin{array}{ll}\text { Abbreviations } \\ \text { MITF } & \text { Microphthalmia-associated transcription factor } \\ \text { SIRT1 } & \text { Sirtuin-1 } \\ \text { FOXO } & \text { Forkhead box O } \\ \text { UV } & \text { Ultraviolet } \\ \text { IL } & \text { Interleukin } \\ \text { HGF } & \text { Hepatocyte growth factor } \\ \text { ET } & \text { Endothelin } \\ \text { KGF } & \text { Keratinocyte growth factor } \\ \text { SCF } & \text { Stem cell factor } \\ \text { bFGF } & \text { Basic fibroblast growth factor } \\ \alpha-M S H & \alpha \text {-melanocyte-stimulating hormone } \\ \text { ROS } & \text { Reactive oxygen species } \\ \text { AMPK } & \text { AMP-activated protein kinase } \\ \text { IGF } & \text { Insulin growth factor } \\ \text { L-DOPA } & \text { L-3,4-dihydroxyphenylalanine } \\ \text { ERK } & \text { Extracellular signal-regulate kinase } \\ \text { GAPDH } & \text { Glyceraldehyde 3-phosphate dehydrogenase }\end{array}$




\section{References}

1. Okazaki, M.; Yoshimura, K.; Uchida, G.; Harii, K. Correlation between age and the secretions of melanocyte-stimulating cytokines in cultured keratinocytes and fibroblasts. Br. J. Dermatol. 2005, 153 (Suppl. 2), 23-29. [CrossRef] [PubMed]

2. Kovacs, D.; Cardinali, G.; Aspite, N.; Cota, C.; Luzi, F.; Bellei, B.; Briganti, S.; Amantea, A.; Torrisi, M.R.; Picardo, M. Role of fibroblast-derived growth factors in regulating hyperpigmentation of solar lentigo. Br. J. Dermatol. 2010, 163, 1020-1027. [CrossRef] [PubMed]

3. Luger, T.A.; Schwarz, T. Evidence for an epidermal cytokine network. J. Investig. Dermatol. 1990, 95 (Suppl. 6), 100S-104S. [CrossRef] [PubMed]

4. Imokawa, G.; Miyagishi, M.; Yada, Y. Endothelin-1 as a new melanogen: Coordinated expression of its gene and the tyrosinase gene in UVB-exposed human epidermis. J. Investig. Dermatol. 1995, 105, 32-37. [CrossRef] [PubMed]

5. Schauer, E.; Trautinger, F.; Kock, A.; Schwarz, A.; Bhardwaj, R.; Simon, M.; Ansel, J.C.; Schwarz, T.; Luger, T.A. Proopiomelanocortin-derived peptides are synthesized and released by human keratinocytes. J. Clin. Investig. 1994, 93, 2258-2262. [CrossRef] [PubMed]

6. Smit, N.; Le Poole, I.; van den Wijngaard, R.; Tigges, A.; Westerhof, W.; Das, P. Expression of different immunological markers by cultured human melanocytes. Arch. Dermatol. Res. 1993, 285, 356-365. [CrossRef] [PubMed]

7. Tomita, Y.; Iwamoto, M.; Masuda, T.; Tagami, H. Stimulatory effect of prostaglandin E2 on the configuration of normal human melanocytes in vitro. J. Investig. Dermatol. 1987, 89, 299-301. [CrossRef] [PubMed]

8. Shin, J.; Kim, J.H.; Kim, E.K. Repeated exposure of human fibroblasts to UVR induces secretion of stem cell factor and senescence. J. Eur. Acad. Dermatol. Venereol. 2012, 26, 1577-1580. [CrossRef] [PubMed]

9. Torres-Alvarez, B.; Mesa-Garza, I.G.; Castanedo-Cazares, J.P.; Fuentes-Ahumada, C.; Oros-Ovalle, C.; Navarrete-Solis, J.; Moncada, B. Histochemical and immunohistochemical study in melasma: Evidence of damage in the basal membrane. Am. J. Dermatopathol. 2011, 33, 291-295. [CrossRef] [PubMed]

10. Howitz, K.T.; Bitterman, K.J.; Cohen, H.Y.; Lamming, D.W.; Lavu, S.; Wood, J.G.; Zipkin, R.E.; Chung, P.; Kisielewski, A.; Zhang, L.L.; et al. Small molecule activators of sirtuins extend Saccharomyces cerevisiae lifespan. Nature 2003, 425, 191-196. [CrossRef] [PubMed]

11. Lin, C.B.; Babiarz, L.; Liebel, F.; Roydon Price, E.; Kizoulis, M.; Gendimenico, G.J.; Fisher, D.E.; Seiberg, M. Modulation of microphthalmia-associated transcription factor gene expression alters skin pigmentation. J. Investig. Dermatol. 2002, 119, 1330-1340. [CrossRef] [PubMed]

12. Bertolotto, C.; Busca, R.; Abbe, P.; Bille, K.; Aberdam, E.; Ortonne, J.P.; Ballotti, R. Different cis-acting elements are involved in the regulation of TRP1 and TRP2 promoter activities by cyclic AMP: Pivotal role of M boxes (GTCATGTGCT) and of microphthalmia. Mol. Cell. Biol. 1998, 18, 694-702. [CrossRef] [PubMed]

13. Bentley, N.J.; Eisen, T.; Goding, C.R. Melanocyte-specific expression of the human tyrosinase promoter: Activation by the microphthalmia gene product and role of the initiator. Mol. Cell. Biol. 1994, 14, 7996-8006. [CrossRef] [PubMed]

14. Newton, R.A.; Cook, A.L.; Roberts, D.W.; Leonard, J.H.; Sturm, R.A. Post-transcriptional regulation of melanin biosynthetic enzymes by cAMP and resveratrol in human melanocytes. J. Investig. Dermatol. 2007, 127, 2216-2227. [CrossRef] [PubMed]

15. Kim, Y.M.; Yun, J.; Lee, C.K.; Lee, H.; Min, K.R.; Kim, Y. Oxyresveratrol and hydroxystilbene compounds. Inhibitory effect on tyrosinase and mechanism of action. J. Biol. Chem. 2002, 277, 16340-16344. [CrossRef] [PubMed]

16. Kairisalo, M.; Bonomo, A.; Hyrskyluoto, A.; Mudo, G.; Belluardo, N.; Korhonen, L.; Lindholm, D. Resveratrol reduces oxidative stress and cell death and increases mitochondrial antioxidants and XIAP in PC6.3-cells. Neurosci. Lett. 2011, 488, 263-266. [CrossRef] [PubMed]

17. Kim, S.Y.; Park, K.C.; Kwon, S.B.; Kim, D.S. Hypopigmentary effects of 4-n-butylresorcinol and resveratrol in combination. Pharmazie 2012, 67, 542-546. [PubMed]

18. Nakae, J.; Biggs, W.H., 3rd; Kitamura, T.; Cavenee, W.K.; Wright, C.V.; Arden, K.C.; Accili, D. Regulation of insulin action and pancreatic $\beta$-cell function by mutated alleles of the gene encoding forkhead transcription factor Foxo1. Nat. Genet. 2002, 32, 245-253. [CrossRef] [PubMed] 
19. Holzenberger, M.; Dupont, J.; Ducos, B.; Leneuve, P.; Geloen, A.; Even, P.C.; Cervera, P.; Le Bouc, Y. IGF-1 receptor regulates lifespan and resistance to oxidative stress in mice. Nature 2003, 421, 182-187. [CrossRef] [PubMed]

20. Hu, M.C.; Lee, D.F.; Xia, W.; Golfman, L.S.; Ou-Yang, F.; Yang, J.Y.; Zou, Y.; Bao, S.; Hanada, N.; Saso, H.; et al. IKB kinase promotes tumorigenesis through inhibition of forkhead FOXO3a. Cell 2004, 117, 225-237. [CrossRef]

21. Paik, J.H.; Kollipara, R.; Chu, G.; Ji, H.; Xiao, Y.; Ding, Z.; Miao, L.; Tothova, Z.; Horner, J.W.; Carrasco, D.R.; et al. FOXOs are lineage-restricted redundant tumor suppressors and regulate endothelial cell homeostasis. Cell 2007, 128, 309-323. [CrossRef] [PubMed]

22. Luo, J.; Nikolaev, A.Y.; Imai, S.; Chen, D.; Su, F.; Shiloh, A.; Guarente, L.; Gu, W. Negative control of p53 by Sir2 $\alpha$ promotes cell survival under stress. Cell 2001, 107, 137-148. [CrossRef]

23. Vaziri, H.; Dessain, S.K.; Ng Eaton, E.; Imai, S.I.; Frye, R.A.; Pandita, T.K.; Guarente, L.; Weinberg, R.A. hSIR2(SIRT1) functions as an NAD-dependent p53 deacetylase. Cell 2001, 107, 149-159. [CrossRef]

24. Huang, H.; Tindall, D.J. Dynamic FoxO transcription factors. J. Cell Sci. 2007, 120, 2479-2487. [CrossRef] [PubMed]

25. Hori, Y.S.; Kuno, A.; Hosoda, R.; Horio, Y. Regulation of FOXOs and p53 by SIRT1 modulators under oxidative stress. PLoS ONE 2013, 8, e73875. [CrossRef] [PubMed]

26. Camins, A.; Sureda, F.X.; Junyent, F.; Verdaguer, E.; Folch, J.; Pelegri, C.; Vilaplana, J.; Beas-Zarate, C.; Pallas, M. Sirtuin activators: Designing molecules to extend life span. Biochim. Biophys. Acta 2010, 1799, 740-749. [CrossRef] [PubMed]

27. Tang, B.L. Sirt1 and the Mitochondria. Mol. Cells 2016, 39, 87-95. [PubMed]

28. Horio, Y.; Hayashi, T.; Kuno, A.; Kunimoto, R. Cellular and molecular effects of sirtuins in health and disease. Clin. Sci. 2011, 121, 191-203. [CrossRef] [PubMed]

29. Ido, Y.; Duranton, A.; Lan, F.; Weikel, K.A.; Breton, L.; Ruderman, N.B. Resveratrol prevents oxidative stress-induced senescence and proliferative dysfunction by activating the AMPK-FOXO3 cascade in cultured primary human keratinocytes. PLoS ONE 2015, 10, e0115341. [CrossRef] [PubMed]

30. Gunschmann, C.; Stachelscheid, H.; Akyuz, M.D.; Schmitz, A.; Missero, C.; Bruning, J.C.; Niessen, C.M. Insulin/IGF-1 controls epidermal morphogenesis via regulation of FOXO-mediated p63 inhibition. Dev. Cell 2013, 26, 176-187. [CrossRef] [PubMed]

31. Kim, J.; Choi, H.; Cho, E.G.; Lee, T.R. FOXO3a is an antimelanogenic factor that mediates antioxidant-induced depigmentation. J. Investig. Dermatol. 2014, 134, 1378-1388. [CrossRef] [PubMed]

32. Ozel Turkcu, U.; Solak Tekin, N.; Gokdogan Edgunlu, T.; Karakas Celik, S.; Oner, S. The association of FOXO3a gene polymorphisms with serum FOXO3a levels and oxidative stress markers in vitiligo patients. Gene 2014, 536, 129-134. [CrossRef] [PubMed]

33. Eisinger, M.; Marko, O. Selective proliferation of normal human melanocytes in vitro in the presence of phorbol ester and cholera toxin. Proc. Natl. Acad. Sci. USA 1982, 79, 2018-2022. [CrossRef] [PubMed]

34. Medrano, E.E.; Nordlund, J.J. Successful culture of adult human melanocytes obtained from normal and vitiligo donors. J. Investig. Dermatol. 1990, 95, 441-445. [PubMed]

35. Choi, H.R.; Kang, Y.A.; Lee, H.S.; Park, K.C. Disulfanyl peptide decreases melanin synthesis via receptor-mediated ERK activation and the subsequent downregulation of MITF and tyrosinase. Int. J. Cosmet. Sci. 2016, 38, 279-285. [CrossRef] [PubMed]

36. Busca, R.; Bertolotto, C.; Ortonne, J.P.; Ballotti, R. Inhibition of the phosphatidylinositol 3-kinase/p70(S6)-kinase pathway induces B16 melanoma cell differentiation. J. Biol. Chem. 1996, 271, 31824-31830. [CrossRef] [PubMed]

37. Ko, H.J.; Kim, H.J.; Kim, S.Y.; Yun, H.Y.; Baek, K.J.; Kwon, N.S.; Wan Kyun, W.; Choi, H.R.; Park, K.C.; Kim, D.S. Hypopigmentary effects of ethyl P-methoxycinnamate isolated from Kaempferia galanga. Phytother. Res. 2014, 28, 274-279. [CrossRef] [PubMed]

(C) 2017 by the authors. Licensee MDPI, Basel, Switzerland. This article is an open access article distributed under the terms and conditions of the Creative Commons Attribution (CC BY) license (http:/ / creativecommons.org/licenses/by/4.0/). 